\title{
A estrutura genética das entificações comunitárias
}

\section{The genetic structure of community entifications}

\author{
EDUARDO YUJI YAMA MOTO* \\ Universidade Estadual do Centro-Oeste. Guarapuava - PR, Brasil
}

* Doutor em

Comunicação pela Universidade Federal do Rio de Janeiro. Professor e pesquisador da Universidade Estadual do Centro-Oeste (Unicentro - PR). Atualmente trabalha com projetos de extensão universitária e de pesquisa em comunicação comunitária. E-mail: yujieduardo@gmail.com

\begin{abstract}
Thinkers of Heideggerian tradition such as Jean-Luc Nancy and Roberto Esposito, through concepts such as being-in-common and communitas, suggest a fundamental ontology of community (Mitsein). This ontology, however, has generated a difficulty of interpretation and operation due to the hegemonic subjectivist paradigm that anticipates the reading of these concepts. This article aims to redescribe this ontology from a referential shift: from the Heideggerian metaphysical universe to the field of "absolute immanence" (Deleuze). This shift allows structuralizing and conferring operational communication to that ontology, as well as observing new political phenomena, such as those made possible by today's technical communication devices.
\end{abstract}

Keywords: Mitsein, desubstancialization, 2013 demonstrations
Palavras-chave: Mitsein, dessubstancialização, protestos 2013 
O que mais impressiona nas manifestações do mês de Maio na China, é de fato, a relativa ausência de conteúdos determinados de reivindicação (democracia, liberdade são noções demasiado genéricas e difusas para constituírem o objeto real de um conflito, e a única exigência concreta, a reabilitação de Hu Yao-Bang, foi imediatamente concedida). Assim, tanto mais inexplicável é a violência da reação do Estado. É provável, todavia, que a desproporção seja apenas aparente e que os dirigentes chineses tenham agido, do seu ponto de vista, com mais lucidez do que os observadores ocidentais, exclusivamente preocupados em fornecerem argumentos à cada vez menos plausível oposição entre democracia e comunismo.

Agamben (1993: 66)

1. Essa distinção é tributária de Jacques Rancière, que separa a "comunidade política" da "policial". Contra a "comunidade policial que tende a saturar a relação dos corpos e das significações, das partes dos lugares e dos destinos" (2010: 428), o autor reivindica uma "comunidade política que reabre os intervalos separando os nomes de sujeitos e os seus modos de manifestação dos corpos sociais e das suas propriedades" (Ibid.).
A

S MANIFESTAÇÕES DE junho de 2013 no Brasil nos mostraram a insuficiência dos atuais aparatos conceituais para análise de novos fenômenos políticos. Elaborados a partir de um princípio dogmático e moral, tais conceitos apresentaram não apenas dificuldade compreensiva como também o desvirtuamento do significado político dessas manifestações (caracterizadas pela efemeridade e diferenciação), convertendo sua potência crítica em conservadorismo.

A base dessa deturpação e precariedade analítica pode ser atribuída à sua própria constituição ontológica: uma vez que esses conceitos se voltam à fixação e identificação de representações, eles tendem a reduzir os novos fenômenos a uma substância ou essência previamente dada; prestam-se à verificação de conteúdos mesmo que, para isso, seja necessária a sua degradação (ajuste ou supressão de seu caráter singular, não subjetivo); não obstante, criminalizam os fenômenos que excedem ou atentam contra os domínios institucionalizados da representação, como os casos do antipartidarismo, do apartidarismo e do anonimato em alguns protestos.

No presente texto, pretendemos dar outro sentido a essas manifestações a partir de uma ampliação cognitiva na estrutura ontológica da comunidade.

Aqui, o destaque à noção de comunidade deve-se às duas formas de associação humana nela pressupostas (vinculação com o mesmo e com o diferente), cuja prática indica duas modalidades políticas correspondentes: o paroquialismo (fechamento em torno de uma substância; ritualização e monitoramento de fronteiras identitárias) e o cuidado de si (libertação das formas substanciais de representação; abertura ao indeterminado, à dessubstancialização). Essa segunda modalidade, na qual a diferença, a multiplicidade ou heterogeneidade se fazem presentes, é onde a crítica (logo, a política efetiva $\left.{ }^{1}\right)$ comparece de maneira mais plena. 
O desejo de eliminação dessa plenitude constitui objetivo das formações paroquiais, em geral, totalitárias.

\section{DESVELAMENTO DA ONTOLOGIA FUNDAMENTAL DA COMUNIDADE}

Para que a leitura política dessas manifestações seja possível é necessário retornarmos a um ponto fundamental, isto é, ao desvelamento da ontologia originária da comunidade. Um passo importante, nesse sentido, foi dado por Jean-Luc Nancy e Roberto Esposito em suas interpretações sobre a noção de comunidade em Heidegger ${ }^{2}$, referida, respectivamente, como ser-em-comum e communitas.

Ser-em-comum (ou estar-em-comum), para Nancy, é o termo que apresenta a premência da abertura ao outro na analítica existencial heideggeriana - esse outro pressuposto numa carga (cum ou mit) oculta em Dasein. No limite, a expressão indicaria o primado da ética sobre a ontologia enquanto filosofia primeira.

O ser-em-comum se define e se constitui por uma carga e, em última análise, não está a cargo de outra coisa senão do mesmo cum. Estamos a cargo de nosso com, ou seja, de nós [...] Cum é algo que nos expõe: põe-nos uns de frente aos outros, nos entrega uns aos outros, nos arrisca uns contra os outros e juntos nos entrega à experiência que não é outra coisa senão a de ser com... (Nancy, 2007: 16).

Communitas, por sua vez, é o correspondente latino para comunidade. Sua desconstrução em dois importantes radicais (cum = presença incontornável de outro; e munus = dever, dívida, obrigação) revela, segundo Esposito, o seu significado arcaico: compartilhamento de uma dívida, abertura incondicional ao outro (qualquer), dessubjetivação.

$\mathrm{O}$ munus que a communitas compartilha não é uma propriedade ou pertença. Não é uma possessão, mas ao contrário, uma dívida, uma prenda, um dom a dar. Um "dever" une os sujeitos da comunidade - no sentido de que "te devo algo", e não no sentido de que "me deves algo" - que faz com que não sejam inteiramente donos de si mesmo. Em termos mais precisos, os expropria, em parte ou inteiramente, sua propriedade inicial, sua propriedade mais própria, ou seja, sua subjetividade (Esposito, 2007: 30-31).

Como se pode observar, as formulações comunitárias de Nancy e Esposito não apenas ampliam o significado convencional da comunidade, mas 
também desenvolvem um importante tópico do pensamento heideggeriano. Tal desenvolvimento, entretanto, ocorre nos limites dessa filosofia: tanto nos textos de Nancy quanto nos de Esposito, pode-se verificar a presença marcante do pensador alemão em conceitos como a diferença ontológica, as determinações do mundo fático (a função conformadora das significâncias, dos mobilizadores estruturais, dos em-virtudes-de), bem como a sua libertação pelo clamor originário.

No que se refere à distinção entre ser e ente, sobretudo no texto de Esposito, comparece a separação fundamental entre o ser da comunidade (Mitsein) e seus modos de ser, ou seja, as suas entificações substancialistas (ou essencialistas), tal como a Gemeinschaft, o neocomunitarismo e a ética da comunicação, além do modo dessubstancialista do ser-em-comum e da communitas.

Diferentemente de Esposito - que chega ao fundamento ontológico da comunidade pela distinção acima -, Nancy irá acessá-lo pela reivindicação daquele traço comum originário do ser (mit ou cum) que é abandonado em proveito de sua emergência solitária.

A comunidade não é um predicado do ser ou da existência. Não se altera nada no conceito de existência adicionando ou extraindo o caráter de comunidade. Mas a comunidade é simplesmente a posição real da existência [...]. Deve implicar que o estar-em-comum, ou o coestar, não se agrega de maneira secundária e extrínseca ao ser-si-mesmo e ao estar-só. Deve-se compreendê-lo como aquilo que Heidegger chamou de Mitsein, e até mesmo de Mitdasein, ainda que sem o devido radicalismo. Com efeito, há que se compreender que o "mit" não qualifica o "sein" (como se o ser subsistira já por si mesmo de uma maneira qualquer, como se o ser fora si-mesmo, ou seja, como se o ser fora ou existira absolutamente), e que o "mit" nem sequer qualifica o "Dasein", mas o constitui essencialmente. Em alemão barroco, dir-se-ia que se trata do "seindamit" ou do "com" enquanto modalidade própria, exclusiva e originária do estar-aí ou do ser-aí (Nancy, 2000: 97-98).

Trilhando caminhos muito parecidos, Nancy e Esposito acabam se encontrando em um mesmo ponto de inflexão: ambos põem em xeque o pressuposto ontológico hegemônico da filosofia ocidental que dá primazia (e autonomia) ao ser sumamente ente, eliminando o vínculo com o solo de sua proveniência. Ao fazê-lo emergir de súbito, eximindo-o desta dívida originária (munus), subtrai-se dele sua dimensão constituinte.

Que dimensão é essa? Mitsein. Ou, para nós, Comunidade.

A palavra Comunidade adotada aqui retoma o seu significado primevo: autoridade externa e sempre presente (virtual), que dos entes exige o reco- 
nhecimento de sua obrigação originária (munus); dever, abertura ou entrega desses às solicitações desse solo comum.

De fato, desde os tempos mais imemoriais, a comunidade sempre designou a instância que introduz o ente no mundo possibilitando a sua existência por meio da vida social integrada, definidora de sua situação existencial na cadeia de reciprocidade e na circulação do munus. Daí a sua feição credora expropriativa que abre e dissolve o ente na integração coletiva (multiplicidade, heterogeneidade). É este significado que se pretendeu dar para Mitsein com o qualificativo comunitário: lugar de proveniência de todo ente, seja o ser platônico-aristotélico, seja o sujeito cartesiano, transcendental ou heideggeriano; exterioridade absoluta, poder-ser que precede cada individuação e solo de procedência de toda ontologia.

Assim, pensar a comunidade em sua ontologia fundamental, mais do que caracterizá-la como entes acabados - seja com relação a si mesmos, seja coletivamente -, implica tomá-los em sua condição originariamente devedora ou imprópria (Mitdasein), o que, nesse caso, não significa alienar-se, entregar-se aos cuidados do mundo, mas ser abertura (estar aberto) aos apelos silenciosos da Comunidade, reconhecendo-se sempre como indeterminação, incompletude, falta, impossibilidade de fechamento ou autossuficiência. É o que revela não só a estrutura semântica de Mitdasein (em que mit indica o vínculo secreto com o seu próprio indeterminado), mas também os seus correspondentes communitas e ser-em-comum, cujo vínculo com a impropriedade constituinte (Comunidade) apresenta-se pelas partículas cum e comum.

A decisão entre acatar esse chamado ou promover um novo abandono (o que não resolveria a questão da dívida que é permanente e virtual) envolve a possibilidade de expansão da vida (existência) para além dos limites de uma ontologia. Essa decisão se apresenta cotidianamente nas mais diversas experiências comunitárias, no modo como o ente intramundano lida com a significância e a impessoalidade de um campo de sentido que vem ao seu encontro com significados já previamente dados e funcionalizados. Exemplos disso são os campos conformativos da Gemeinschaft, do neocomunitarismo e da ética da comunicação, nos quais os entes se encontram de início e na maioria das vezes. Vale lembrar que esses campos - enquanto disposição apaziguadora, defensiva (in-munizante), voltada à instauração da "segurança ontológica" (Giddens, 1991) - acomodam os entes de tal modo que os eximem da responsabilidade pelo cuidado de si, impossibilitando a experimentação de si (ampliação da vida) para além da substância comum.

Por outro lado, pode-se também decidir pela dessubstancialização (ser-em-comum e communitas), modo de ser da comunidade que conduz o ente 


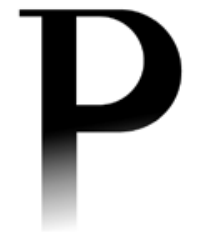

3. A noção heideggeriana de cuidado (Sorge ou cura) é aqui compreendida como modo de manutenção da abertura dos entes à diferença ontológica, o que evitaria uma totalização substancial.

Nesse aspecto, assemelhase ao cuidado-de-si foucaultiano (epiméleia heautôे), tanto no sentido de combate ao absolutismo da identidade subjetiva, quanto na produção de si como obra de arte (estética da existência) - constante reelaboração identitária como forma de resistência aos dispositivos biopolíticos de sedentarização.

4. Esposito (2007: 161-162) fala de um "objetivo da comunidade" enquanto assunção da "consciência de nossa

'impropriedade"'; isso porque "o comportamento 'autêntico' não consiste em desfazer-se do 'inautêntico', mas assumilo como tal. E, portanto, em cuidar-se". à indeterminação originária, porque nela o esvaziamento subjetivo o põe em contato com o seu próprio (o poder-ser), abrindo a crise que o põe à prova, exigindo a sua própria reinvenção (cuidado de si) ${ }^{3}$. Ser-para-a-morte (Sein zum Tode), como implicado na dessubstancialização, produz a abertura do ente (des-in-munização) e o desligamento com as estruturas conformativas de sentido do mundo fático. O ente, então, é suspenso, obrigado a projetar um campo existenciário onde será indefinidamente jogado.

O desligamento com os modos tutelares e subjetivantes da facticidade comunitária interrompe os automatismos sociais e acende a possibilidade para as diversas formas de existência, oferecendo-se como saída ao essencialismo comunitário que exclui as singularidades advindas dos mais diversos encontros humanos. A dessubstancialização, embora assuma como tarefa o cuidado para com o ente tal como a mundaneidade heideggeriana, não se confunde com esta porque conduz o ente à condição de faltante ou devedor (revogando a sua segurança, plenitude e absolutismo), lembrando o ente de seu vínculo (cum) com o solo de sua proveniência e, desse modo, da incerteza de seu destino. A tutela a que o ser-em-comum e a communitas sugerem, portanto, é o cuidado de si - e também do outro, visando à sua libertação - enquanto responsabilidade para com a expansão da vida; compromisso do ente com a Comunidade (virtual e soberana) dada a conscientização $0^{4}$ de sua dívida e inautenticidade originária.

O cuidado determina a comunidade tanto quanto essa àquela. Não poderia existir uma sem a outra: "cuidado-em-comum". Mas isso quer dizer que a comunidade não tem o "dever" de nos liberar do cuidado, mas, pelo contrário, o dever de custodiá-lo como o único que a faz possível. Essa colocação explica a distinção heideggeriana entre duas modalidades diferentes - e opostas - de "procurar" pelo outro com quem compartilhamos a existência: por uma parte suplantá-lo, tomar seu lugar, para liberá-lo do cuidado; por outra, induzi-lo ao cuidado, liberá-lo não do, mas para o seu cuidado: "Esse procurar, que concerne essencialmente ao cuidado autêntico, ou seja, à existência dos outros, e não a algo que eles cuidam, ajuda os outros a se tornarem conscientes em relação ao próprio cuidado, e livre para ele". Mas como isso é possível? O que significa ajudar os outros? Segundo Heidegger, o único modo não invasivo nem substitutivo com relação ao outro é decidir "deixá-lo ser" em sua alteridade em relação a si mesmo, ou seja, em sua autêntica inautenticidade, ou sua impropriedade mais própria (Esposito, 2007: 162-163).

Essa ontologia fundamental da comunidade, acessada através da communitas e do ser-em-comum, mais do que acrescer um significado à noção con- 
vencional, permite, com efeito, uma ontologia propriamente comunitária para a comunidade. Uma ontologia que toma como ponto de partida não mais o indivíduo, o sujeito ou qualquer outra imagem subjetivista (cogito, consciência, Ego etc.) que desponta à custa da eliminação de Mitsein. Mas, do contrário, que o faz presente em sua realidade ôntica (virtual) tanto quanto em sua origem absoluta: Comunidade como medida de si mesma e para si mesma. $\mathrm{O}$ que decorre dessa mudança paradigmática? O que significa pensar a comunidade segundo uma ontologia comunitária (e não mais subjetivista, personalista ou imunitária)?

\section{A ESTRUTURA DAS ENTIFICAÇÕES COMUNITÁRIAS}

Ora, a dificuldade de se compreender a concepção comunitária de Nancy e Esposito advém precisamente desse paradigma subjetivista que se antepõe e interpreta a comunidade sempre a partir do sujeito ou do indivíduo: comunidade enquanto vontade coletiva, um conjunto de indivíduos iguais ou uma grande (e unificada) subjetividade ${ }^{5}$. Por tal paradigma, expressões como ser-com, ser-junto, ser-uns-com-os-outros, nada-em-comum, reiteradas por Nancy e Esposito, quando não são objetivadas numa unidade ou representação (um território, uma ideologia ou cultura), caem na dimensão insondável do vazio, do abismo indiferenciado, suscitando, com frequência, ambiguidade e inoperância aplicativa. Essa confusão pode estar relacionada à própria inscrição de Mitsein nos projetos hermenêutico (da facticidade) e analítico-existencial de Ser e tempo, que reiteram a hegemonia do referido paradigma, uma vez protagonizada pela figura sintética de Dasein ${ }^{6}$.

Para sair dessa situação, propomos um deslocamento à questão do transcendental tal como formulada por Gilles Deleuze 7 . O transcendental, segundo ele, refere-se ao âmbito das determinações que recaem sobre os entes, destacando-se pelo seu caráter impessoal, neutro e pré-individual e fundamentalmente pelas linhas de força que o constitui, impossibilitando a permanência de qualquer unidade substancial autodeterminante.

A depuração que Deleuze faz do transcendental, excluindo toda forma de consciência imediata (intencionalidades ou retenções puras), termina por conduzi-lo a um lugar estranho à fenomenologia porque é anterior tanto ao sujeito, quanto ao próprio transcendental fenomenológico. Desse lugar - denominado também imanência absoluta, puro plano de imanência ou simplesmente uma vida... -, Deleuze não apenas extrai a sua composição (multiplicidade) como sugere o seu estudo ou experimento (empirismo superior).
5. Esse paradigma pode ser observado como matriz cognitiva da sociologia europeia, conforme a historicização empreendida por Robert Nisbet: "De 1500 a 1800 , toda a secular teoria do direito natural estava preocupada quase que exclusivamente em elaborar uma teoria social. Por trás da imagem racionalista da sociedade que prevalecia nesse período, havia sempre a imagem precedente de indivíduos livres por natureza, que se haviam vinculados racionalmente num modo específico e limitado de associação. O homem era o elemento primário, as relações sociais o elemento secundário. As instituições nada mais eram senão as projeções de sentimentos fixos e adormecidos, inatos ao ser humano. A volição, o consentimento e o contrato são os pontos-chave da visão jusnaturalista da sociedade" (Nisbet, 1966: 48 , grifo meu).

6. Vale observar que as interpretações que arrolam Ser e tempo a um ideário nazista têm como premissa esse paradigma subjetivista, isto é, Mitsein enquanto ser substancial. Os próprios conceitos de impessoalidade (conformadora do Eu) e singularidade (ser-si-mesmo) nessa obra - que em Deleuze assumem um significado antissubjetivista endossam essa subjacente premissa.

7. O transcendental é um termo da epistemologia kantiana para designar as condições a priori de uma experiência, as possibilidades humanas de se conhecer algo previamente. Segundo Deleuze, embora Kant... 


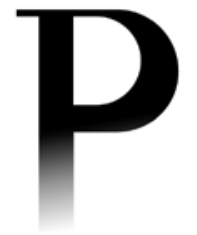

...tenha descoberto esse conceito, ele não o levou até as ultimas consequências, sucumbindo ao "psicologismo" (paradigma subjetivista): "de todos os filósofos, Kant foi o que descobriu o prodigioso domínio do transcendental [...] Entretanto, que fez ele? Na primeira edição da Crítica da Razão Pura, ele descreve em detalhe três sínteses que medem a contribuição respectiva das faculdades pensantes,

culminando todas na terceira, a da recognição, que se exprime na forma do objeto qualquer como correlato do Eu penso, ao qual todas as faculdades se reportam. É claro, assim, que Kant decalca as estruturas ditas transcendentais sobre os atos empíricos de uma consciência psicológica: a síntese transcendental da apreensão é diretamente induzida de uma apreensão empírica” (Deleuze, 1988: 224, grifo meu).

Mas o que esse lugar pode nos revelar para pensarmos a comunidade segundo um paradigma comunitário? Ou ainda: por que lançar mão de Deleuze para elucidarmos a Comunidade, sendo que ele sequer a tomou como objeto particular de reflexão?

Em primeiro lugar, convém explicitar o que significa pensar a comunidade a partir de um paradigma comunitário. Já o vimos: significa restituir nossa dívida originária (munus) para com o pré-ontológico (Mitsein), considerando os entes em geral - sejam individuais ou coletivos (por exemplo, uma comunidade) - enquanto apresentação ou derivação desse domínio. Para não retornarmos à figura ontológica unitária ou cairmos no abismo que supostamente a circunda (pressupostos do paradigma subjetivista), lançamos mão do transcendental deleuzeano. Esse funcionaria como modelo de um campo sem sujeito ou consciência constituidora - do contrário, uma instância de dessubjetivação -, onde as referidas imagens subjetivistas são substituídas pela dinâmica das singularidades e multiplicidades originárias, fazendo ressoar a potência genética do transcendental (que talvez Kant não percebera), sua intensidade criadora.

As multiplicidades são a própria realidade, e não supõem nenhuma unidade, não entram em nenhuma totalidade e tampouco remetem a um sujeito. As subjetivações, as totalizações, as unificações são, ao contrário, processos que se produzem e aparecem nas multiplicidades. Os princípios característicos das multiplicidades concernem a seus elementos, que são singularidades; a suas relações, que são devires; a seus acontecimentos, que são hecceidades (quer dizer, individuações sem sujeito); a seus espaços-tempos, que são espaços e tempos livres; a seu modelo de realização, que é o rizoma (por oposição ao modelo da árvore); a seu plano de composição, que constitui platôs (zonas de intensidade contínua); aos vetores que as atravessam, e que constituem territórios e graus de desterritorialização (Deleuze; Guattari, 2009a: 8).

A ideia de multiplicidade, nesse caso, retoma importantes questões da ontologia, tais como o extemporâneo, o pré-individual e a diferença (pensada em si mesma) presentes em autores como Nietzsche (dispositivo "vontade de poder $\leftrightarrow$ eterno retorno"), Gilbert Simondon (fases da individuação) e Henri Bergson (duração e diferenciação).

Quanto à segunda questão, embora o tema da comunidade passe ao largo dos interesses de Deleuze, sua análise crítica e descritiva do campo transcendental serve-nos como uma ponte para o comportamento compositivo de Mitsein, a partir do qual se pode reivindicar um comportamento semelhante. 
Isso será fundamental para a estruturação desse solo originário comum e, portanto, um paradigma comunitário operacionalizável.

A expressão deleuzeana "estrutura dupla do acontecimento" é aqui de extrema importância, já que traz os componentes elementares desse campo (singularidade, série, devir, hecceidade), bem como o modo como eles se dispõem entre si. É necessário, todavia, definirmos bem esses conceitos, a começar pela palavra estrutura.

Em Deleuze, ela assume um significado muito particular. Trata-se de uma distribuição serializada de "singularidades", em que subjetivações, totalizações e unificações coexistem com hecceidades, blocos de devir, platôs e linhas de fuga. No registro da linguagem, tal estrutura aparece como reunião de pontos singulares formando uma dualidade serial (significante/significado) percorrida e dinamizada pelo sentido (elemento paradoxal); já no domínio ontológico, como multiplicidade em constante movimento (matéria métrica e inextensa, molaridade e molecularidade, ser e devir)'

Nessa concepção estrutural, como se observa, as determinações subjetivistas dão lugar ao princípio da relação diferencial enquanto fundamento de uma gênese ontológica. São essas relações que permitem a individuação de um ente individual ou coletivo (identidades e subjetividades), a emergência de uma substância comum (uma ideologia ou moral), bem como a própria vinculação desses entes a um campo de significação. Fala-se, nesse caso, de uma hecceidade, individuação resultante de uma relação entre singularidades.

O fato do ser individuado ser tomado como estrutura originária - ignorando o "mundo pululante das singularidades anônimas e nômades, impessoais, pré-individuais" (Deleuze, 2007: 106) - tem legitimado as constantes vigilâncias epistemológicas e as práticas de exclusão das diferenças, tais como certas políticas totalitárias que tentam calar a crítica e sufocar os processos naturais de diferenciação interna, as cisões identitárias.

A ideia de um duplo acontecimento na estrutura, trazida por Deleuze, restaura a originariedade não do ser individuado (germe do totalitarismo), mas das singularidades do campo transcendental. É a voz de Mitsein que ressurge aos seres individuados como lembrança de nosso poder-ser. De fato, enquanto entes conformados a uma individuação (a um modo de ser apenas) excluímos este duplo do acontecimento (o ideal, puro, inefetuável) que nos indetermina.

Em todo acontecimento existe realmente o momento presente da efetuação, aquele em que o acontecimento se encarna em um estado de coisas, um indi-
8. Entenda-se por singularidade, "o ponto de partida de uma série que se prolonga sobre todos os pontos ordinários do sistema até a vizinhança de uma outra singularidade" podendo engendrar outra série, que ora converge, ora diverge em relação à primeira (Deleuze, 1988: 438). A relação entre singularidades se dá com todo o campo ressoado assegurando um equilíbrio metaestável e, portanto, um campo de pura diferença.

9. Eis porque, segundo Deleuze (2007: 53), “é inexato opor a estrutura e o acontecimento": "Uma estrutura comporta em todo caso duas distribuições de pontos singulares correspondendo a séries de base [...] a estrutura comporta um registro de acontecimentos ideais, isto é, toda uma história que lhe é interior". 


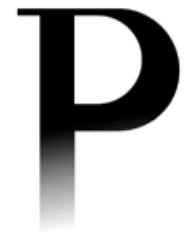

10. O acontecimento efetuado permanece preso no corpo e no espaçotempo, mas o Homem e o contraefetuado vão além, "mais longe do que teríamos acreditado poder. Tanto quanto o acontecimento puro se aprisiona para sempre na sua efetuação, a contra-efetuação o libera sempre para outras vezes"

(Deleuze, 2007: 164).

víduo, uma pessoa, aquele que designamos dizendo: eis aí, o momento chegou; e o futuro e o passado do acontecimento não se julgam senão em função desse presente definitivo, do ponto de vista daquele que o encarna. Mas há, de outro lado, o futuro e o passado do acontecimento tomado em si mesmo, que esquiva todo presente, porque ele é livre das limitações de um estado de coisas, sendo impessoal e pré-individual neutro nem geral nem particular, eventum tantum...; ou melhor, que não há outro presente além daquele do instante móvel que o representa, sempre desdobrado em passado-futuro, formando o que é preciso chamar a contra-efetuação (Deleuze, 2007: 154).

A estrutura percebida em sua forma dupla (não apenas Sein, mas Mitsein) obriga que toda substancialização, toda efetuação de uma substância individuada em um corpo individuado seja também outro a ser contraefetuado, isto é, levado para além dos limites encarnados. Contraefetuar, segundo Deleuze, é não se limitar ao acontecimento; é criar linhas de fuga (cum ou mit), descobrir uma nova superfície ${ }^{10}$. Atitudes como interpretar, representar e ressentir o acontecimento suprimem a contraefetuação, uma vez que nos fazem retornar ao mesmo ou aprofundarmo-nos no ocorrido.

Se estivermos habituados a considerar apenas uma parte do acontecimento (o efetuado) e, em geral, a resigná-lo, condenando-o como infortúnio, Deleuze nos lembra daquele que nos precede e ultrapassa, e para quem devemos sempre saldar quando sobrevém, ser digno de sua presença, querer morrer por ele, inclusive: Mitsen (Comunidade).

Aqui não há nada de ontológico: não se trata de uma anacrônica convocação de guerra, a obediência a uma entidade suprema, mas de uma figuração ética, em que morrer significa dessubjetivar, ampliar a vida. Abrir-se ao outro (qualquer) visando não reafirmar a minha posição ou elevar-se, pela síntese do negativo, a um patamar superior, mas superarmo-nos, conjuntamente, a disposição limitadora da subjetividade unificada e da substância comum. Portanto, é uma figuração política também, e talvez a mais radical, pois implica que cada efetuação (que é incessante e inevitável) seja circunstância para uma crítica, tanto quanto para um cuidar-se de si e do outro (Sorge).

Curioso perceber que essa ética ou política tem se intensificado em anos recentes, sobretudo com os meios de comunicação que fazem ecoar a voz de Mitsein. Como observaram Antonio Lafuentes e Alberto Cursin Jimenez, ao dar visibilidade às demandas sociais, esses meios amplificam as disputas pela substância comum, fissurando a estrutura rígida unitária, "formando o que é preciso chamar a contraefetuação": 
O bem comum é uma construção abstrata, caridosa e teledirigida, exceto quando podemos discuti-lo ou, mais precisamente, quando tem sentido para mim, quando minha conduta lhe dá sentido, quando posso reagir a sua proclamação, advento ou concessão. Contraefetuar a AIDS foi desenhar uma estratégia para enfrentar todos os determinismos iniciais que a acompanhavam, porque é verdade que no início a AIDS se fez eficaz como uma condenação à morte contra os gays, o que felizmente provocou uma rebelião, uma contraefetuação, que converteu os afetados em protagonistas de sua cura. As comunidades de atingidos se visibilizam em um processo de contraefetuar o ditame, o instituído, o consensual e, finalmente o que é imposto. Contraefetuar, então, é um gesto que se compadece com ações do tipo trazer à tona, por em relevo, dar um passo para frente ou colocar holofotes. Práticas que participam da ideia-chave do que queremos dizer: tornar visível algo, mostrando o contexto de onde sai (Lafuentes; Corsín Jiménez, 2011: 20).

É inegável que os meios de comunicação, ao colocarem holofotes sobre o tecido dissensual de uma comunidade, intensificam aquilo que Deleuze e Guattari (2009b) chamaram de uma "desterritorialização relativa do capital", a abertura de um feixe infinito de relações.

A questão, todavia, é observar, dentro de nosso escopo comunicacional, como se opera a contraefetuação nesse contexto: acompanhar as linhas de força que nos levam a uma experiência ético-política ou cair em um novo totalitarismo?

\section{PARA LER OS NOVOS FENÔMENOS}

A onda de protestos que arrebatou o país em 2013 trouxe essa dupla perspectiva: seguir uma imanência ou uma transcendência comunitária?

Caracterizados por reivindicações múltiplas e pelo caráter efêmero de suas aparições (gravadas e transmitidas para a web), esses protestos têm sido pouco compreendidos pelos analistas que insistem em enquadrá-los nos parâmetros teóricos da política tradicional (vale dizer substancialista). Ao procederem dessa maneira, eles ignoram aquilo que foge de seus enquadramentos ou que ameaçam o regime da representação, tais como a dessubstancialização e a contraefetuação comunitária.

Embora se atribua ao início dessas manifestações o aumento da tarifa dos transportes públicos, sancionado em várias capitais brasileiras, não convém buscá-las em substancializações pontuais (redução de tarifas, reformas políticas $)^{11}$, mas de seguir as linhas que as atravessam sem se esgotarem em suas
11. Como outros analistas observaram, essas manifestações provêm de uma insatisfação generalizada decorrente de outros protestos anteriores: contra a desocupação do Pinheirinho (São José dos Campos), a construção da Usina Hidrelétrica de Belo Monte (Altamira), a expropriação de territórios indígenas (Guarani-Kaiowá), a cura gay etc. 
12. "Quando se grita 'sem partido’ nós vemos aí um grande pedido. E não há democracia sem partido. Não há democracia sem uma forma mínima de instituição. Sem partido, no fundo, é ditadura." (Carvalho, apud Mendes, 2013). efetuações. Isso porque a fixação sobre elas, ou a busca por figuras subjetivistas (o partido político, o líder do movimento etc.), deixa escapar aquilo que julgamos fundamental nesse evento: o chamado de Mitsein.

Através de plataformas como o Facebook, o Instagram e o Twitter, esse chamado intensificou-se na linguagem de tais dispositivos (\#VemPraRua, \#OccupySP, \#PrimaveraBrasileira, \#PasseLivre etc.). Podemos aqui utilizar a nossa estrutura das entificações comunitárias e descrever dualidades seriais singularidades no plano do ente comunitário (individual ou coletivo) e outras no ciberespaço (viralizado por fotos, vídeos e hashtags), ou na rua (por entre cartazes, pichações e palavras de ordem) -, cujo ponto de fusão entre os planos compõem comunidades (hecceidades).

Nesse convite a comunizar ressoa o clamor de Mitsein à exposição dos corpos aos choques e afetações da multidão que produzem desprendimentos orgânicos, liberando-os para o cuidado de si. Lembremos aqui: Mitsein chama, mas não decide pelos corpos, pois é impessoal, neutro e impassível; no limite indica a eles os modos de ser da comunidade, seja sob postura substancialista ("O gigante acordou"; "Somos a rede social"; "Jesus é 10, educação e saúde é zero"), ou dessubstancialista ("Não fujo à luta, mas não sou tua filha"; "Não são só 20 centavos"; "Sem moralismo”).

Importante observar, nesses dois modos de ser da comunidade, dois diferentes tipos de cuidado: enquanto o segundo reivindica um não querer mais ser cuidado, o primeiro propõe a submissão aos tradicionais sistemas representativos (Estado, Igreja, partidos políticos e sindicatos) que passam a ser seus procuradores legítimos no tocante à segurança ontológica e às deliberações institucionais.

A leitura que muitos fizeram dessas manifestações, ao interpretá-las (apenas) com as ferramentas da política representativa, foi de que a recusa à totalização (seja partidária, nacionalista ou moralista) era conservadora - exemplar aqui a declaração do ministro da Secretaria Geral da Presidência da República, Gilberto Carvalho, que enquadrou o apartidarismo e o antipartidarismo dos manifestantes como um desejo de retorno à "ditadura"12. Todavia, o que tais protestos trazem é a recusa à tutela do governo.

De fato, a maneira como operam os sistemas totalitários representativos ao interpretar os fenômenos que fogem de seu alcance, ou que os ameaçam, é invertendo a própria ideia de política, transformando a libertação das estruturas da facticidade comunitária em uma potência de salvação que paralisa a vida e o vitalismo ingovernável.

Ali não faltaram aqueles que, de alguma maneira, tentaram cuidar de nós: colunistas da grande mídia, apresentadores de programas policiais e sumida- 
des da internet, líderes políticos, religiosos e militares, especialistas, além, é claro, dos próprios intelectuais. Nessa última categoria, destacamos Marilena Chauí e a sua leitura sobre esses novos fenômenos políticos, a exemplo dos grupos adeptos da estratégia black bloc, cujos atos radicais foram por ela classificados como "fascismo". Para Chauí, esse "grupo" não é anarquista, como alguns se autodenominam, nem usam da "violência revolucionária", algo que, para a filósofa, "só se realiza se há uma visão do que é inaceitável no presente e qual a institucionalidade futura que se pretende construir" (Black..., 2013).

A "linguagem intempestiva" de tal movimento, segundo ela, deveria ser substituída pela criação de outras bandeiras e pela "reforma política e tributária”.

Essa legítima preocupação com as mediações políticas, entretanto, deixa de lado o fato de que esses novos fenômenos já são uma bandeira, embora muito diferente daquela dos partidos cujo reconhecimento se desenvolve dentro dos marcos da institucionalidade. Uma bandeira que busca a sua afirmação não enquanto partido político, grupo fascista ou de extrema esquerda, mas enquanto singularidade.

Eles não se enquadram na categoria do fascismo, primeiramente, porque (como a própria autora observou) falta "institucionalidade futura"; em segundo lugar, porque seus ataques não atentam contra a vida, mas contra os objetos que as apequenam (carros de luxo, fast-foods, bancos, serviços públicos precários). Diversamente, a vida enquanto potência de realização humana é que deve ser protegida, assegurada ou liberta dos aparatos governamentalizados (a polícia militar, a administração pública). Nesse sentido, e para além dos reformismos, eles parecem mirar devires como comunidade política. É esse o ponto que merece ser enfatizado: tais fenômenos são blocos de devir, nasceram de uma cisão (quiçá do anarquismo) e visam à dessubstancialização comunitária. Foram emblemáticas suas últimas aparições em 2013 durante a Copa das Confederações e os desfiles de 7 de setembro, eventos celebratórios de uma totalização.

Isso nos remete a outro ponto importante e que os tem destacado da imensa massa de protestos: o uso de máscaras. Vemos aí, tal como observou Richard Sennett, a manifestação da finitude do personalismo na política e na sociabilização; um gesto de autodistanciamento de si imprescindível à contraefetuação. Não é à toa que os agentes da sedentarização estão entre os seus críticos mais severos, acenando para o retorno ao psicológico, à política das alianças familiaristas e ao governo tutelar.

Para recobrar aquela significação obsoleta de civilidade e relacioná-la ao frêmito da vida pública, eu definiria civilidade da seguinte maneira: é a atividade que 
protege as pessoas umas das outras e ainda assim permite que elas tirem proveito da companhia umas das outras. Usar máscara é a essência da civilidade. As máscaras permitem a sociabilidade pura, separada das circunstâncias do poder, do mal-estar e do sentimento privado daqueles que as usam. A civilidade tem como objetivo a proteção dos outros contra serem sobrecarregados por alguém (Sennett, 1995: 323).

Por trás dessas máscaras, portanto, habitam grandes interrogações sobre nossa moral (cultura) que não podem ser julgadas de maneira simplista como a mídia atualmente o faz. Por que é tão difícil abrir mão de nossa segurança ontológica? Por que ressentimos (e não contraefetuamos) os eventos que nos fazem distanciarmo-nos de nós mesmos? E por que condenamos as figuras antissubjetivas?

Até agora, o que parece claro sobre esses novos fenômenos políticos é que suas ações não são contra a vida ou o capitalismo em si (tal como poderia remeter a autodenominação anarquista dos black blocs), mas contra as suas formas sedentárias: a democracia representativa, a tradicional política reformista. A título de trabalhos posteriores, seria interessante verificar oscilações sociais a partir desses protestos - por exemplo, um despertar para Sorge. Obviamente não ao redor de um indivíduo ou comunidade, mas a despeito deles.

\section{REFERÊNCIAS}

AGAMBEN, G. A comunidade que vem. Lisboa: Presença, 1993.

BLACK blocs agem com inspiração fascista, diz filósofa a PMs do Rio. Folha de São Paulo, São Paulo, 2013. Disponível em: <http://www1.folha.uol. com.br/fsp/poder/126068-black-blocs-agem-com-inspiracao-fascista-diz-filosofa-a-pms-do-rio.shtml>. Acesso em: 28 set. 2013.

DELEUZE, G. Diferença e repetição. Rio de Janeiro: Graal, 1988.

. Lógica do sentido. São Paulo: Perspectiva, 2007.

DELEUZE, G.; GUATTARI, F. Mil platôs: capitalismo e esquizofrenia (v. 1). São Paulo: Editora 34, 2009a.

. O que é a filosofia? São Paulo: Editora 34, 2009b.

ESPOSITO, R. Communitas: origen y destino de la comunidad. Buenos Aires: Amorrortu, 2007.

GIDDENS, A. As consequências da modernidade. São Paulo: UNESP, 1991.

HEIDEGGER, M. Ser e tempo. Tradução Márcia S. C. Schuback. Petrópolis: Vozes, 2011. 
LAFUENTE, A.; CORSÍN JIMÉNEZ, A. Comunidades de atingidos, o comum e o dom expandido. Revista Galáxia, São Paulo, v. 11, n. 21, p. 1025, jun. 2011.

MENDES, P. 'Sem partido, no fundo, é ditadura', critica ministro Gilberto Carvalho. G1, 21 jun. 2013. Disponível em: < http://g1.globo.com/politica/ noticia/2013/06/sem-partido-no-fundo-e-ditadura-critica-ministro-gilberto-carvalho.html>. Acesso em: 28 set. 2013

NANCY, J-L. La comunidad inoperante. Santiago, Chile: ARCIS, 2000. . Conloquium. In: ESPOSITO, R. Communitas: origen y destino de la comunidad. Buenos Aires: Amorrortu, 2007. p. 09-19.

NISBET, R. The sociological tradition. Nova York: Basic Book, 1966.

RANCIËRE, J. Comunidade como dissentimento. In: DIAS, B. P.; NEVES, J. (Orgs.). A política dos muitos: povo, classes e multidão. Lisboa: Tinta da China, 2010. p. 425-436.

SENNETT, R. O declínio do homem público: as tiranias da intimidade. São Paulo: Companhia das Letras, 1995.

Artigo recebido em 28 de outubro de 2014 e aprovado em 28 de abril de 2015 . 
